\title{
Association between Plasma 25-Hydroxyvitamin D and Breast Cancer Risk
}

\author{
Katherine D. Crew ${ }^{1,2,3}$, Marilie D. Gammon ${ }^{8}$, Susan E. Steck ${ }^{9}$, Dawn L. Hershman $1,2,3$, \\ Serge Cremers ${ }^{4}$, Elzbieta Dworakowski ${ }^{4}$, Elizabeth Shane ${ }^{4}$, Mary Beth Terry 2,3 , Manisha \\ Desai $^{3,5}$, Susan L. Teitelbaum ${ }^{7}$, Alfred I. Neugut ${ }^{1,2,3}$, and Regina M. Santella ${ }^{3,6}$ \\ ${ }^{1}$ Department of Medicine, Division of Hematology/Oncology, College of Physicians and Surgeons, \\ Columbia University \\ 2Department of Epidemiology, Mailman School of Public Health, Columbia University \\ ${ }^{3}$ Herbert Irving Comprehensive Cancer Center, Columbia University \\ ${ }^{4}$ Department of Medicine, Division of Endocrinology, College of Physicians and Surgeons, \\ Columbia University \\ ${ }^{5}$ Department of Biostatistics, Mailman School of Public Health, Columbia University \\ ${ }^{6}$ Department of Environmental Health Sciences, Mailman School of Public Health, Columbia \\ University \\ ${ }^{7}$ Department of Community and Preventive Medicine, Mt. Sinai School of Medicine, New York, \\ New York \\ ${ }^{8}$ Department of Epidemiology, University of North Carolina, School of Public Health, Chapel Hill, \\ North Carolina \\ ${ }^{9}$ Department of Epidemiology and Biostatistics, Arnold School of Public Health, Columbia, South \\ Carolina
}

\section{Abstract}

\begin{abstract}
Vitamin D has been associated with decreased risk of several cancers. In experimental studies, vitamin $\mathrm{D}$ has been shown to inhibit cell proliferation and induce differentiation and apoptosis in normal and malignant breast cells. Using a population-based case-control study on Long Island, New York, we examined the association of breast cancer with plasma 25-hydroxyvitamin D (25OHD) levels, a measure of vitamin D body stores. In-person interviews and blood specimens were obtained from 1,026 incident breast cancer cases diagnosed in 1996 to 1997 and 1,075 populationbased controls. Plasma 25-OHD was measured in batched, archived specimens by Diasorin RIA. The mean (SD) plasma 25-OHD concentration was $27.1(13.0)$ and $29.7(15.1) \mathrm{ng} / \mathrm{mL}$ in the cases and controls, respectively $(P<0.0001)$. Plasma $25-\mathrm{OHD}$ was inversely associated with breast cancer risk in a concentration-dependent fashion $\left(P_{\text {trend }}=0.002\right)$. Compared with women with vitamin D deficiency (25-OHD, $<20 \mathrm{ng} / \mathrm{mL}$ ), levels above $40 \mathrm{ng} / \mathrm{mL}$ were associated with decreased breast cancer risk (odds ratio, $0.56 ; 95 \%$ confidence interval, $0.41-0.78$ ). The reduction in risk was greater among postmenopausal women (odds ratio, 0.46; 95\% confidence interval, $0.09-0.83$ ), and the effect did not vary according to tumor hormone receptor status. In summary,
\end{abstract}

(C)2009 American Association for Cancer Research

Requests for reprints: Katherine D. Crew, Department of Medicine, Division of Hematology/Oncology, Columbia University, 161 Fort Washington Avenue 10-1072, New York, NY 10032. Phone: 212-305-1732; Fax: 212-305-0178; kd59@ columbia.edu..

Disclosure of Potential Conflicts of Interest No potential conflicts of interest were disclosed. 
these results add to a growing body of evidence that adequate vitamin $\mathrm{D}$ stores may prevent breast cancer development. Whereas circulating $25-\mathrm{OHD}$ levels of $>32 \mathrm{ng} / \mathrm{mL}$ are associated with normal bone mineral metabolism, our data suggest that the optimal level for breast cancer prevention is $\geq 40 \mathrm{ng} / \mathrm{mL}$. Well-designed clinical trials are urgently needed to determine whether vitamin $\mathrm{D}$ supplementation is effective for breast cancer chemoprevention.

Breast cancer is the most common cancer among women in the United States. Due to the magnitude of this disease, considerable research effort has been directed toward identifying breast cancer risk factors to target for prevention. However, relatively few modifiable lifestyle and environmental factors have been associated with reduced breast cancer risk. Chemoprevention refers to altering the carcinogenesis process with a drug intervention. The antiestrogens, tamoxifen and raloxifene, are the only drugs that have been approved by the U.S. Food and Drug Administration for breast cancer prevention in high-risk populations. Due to serious toxicities associated with these agents, namely endometrial cancer and thromboembolic disease, they have not gained widespread acceptance in the primary prevention setting. In addition, these antiestrogens do not lower the incidence of more aggressive estrogen receptor (ER)-negative breast cancers, which account for about one third of all breast tumors and are associated with a poorer prognosis compared with ERpositive cancer.

Vitamin $\mathrm{D}$ is a fat-soluble vitamin that regulates calcium and bone homeostasis but also has diverse biological effects relevant to carcinogenesis. Modest amounts of vitamin D come from dietary sources such as fortified dairy products and cereals, fatty fish, and supplements. However, the majority of vitamin D, up to $90 \%$, is produced naturally in the body when UVB light hits a precursor molecule in the skin. Vitamin D then undergoes a series of hydroxylation steps in the liver to yield 25-hydroxyvitamin D (25-OHD), the major circulating metabolite, and in the kidney to produce 1,25-dihydroxyvitamin D [1,25$(\mathrm{OH})_{2} \mathrm{D}$, the most biologically active form. $1,25-(\mathrm{OH})_{2} \mathrm{D}$ exerts its effects in tissues traditionally linked with mineral metabolism, such as bone, kidney, and intestine, by binding to the vitamin D receptor. In addition, extrarenal vitamin D activation occurs in diverse target tissues, such as the colon, prostate, and breast, which express the activating enzyme (1 $\alpha$-hydroxylase) and the vitamin $\mathrm{D}$ receptor, to locally regulate cell turnover $(1,2)$.

Activated vitamin D exerts its antitumor effects via the vitamin $D$ receptor to form a nuclear receptor-ligand complex, which regulates the expression of target genes such as $p 21, p 27, c$ fos, and c-myc (2).

Ecological studies have associated increased solar UVB irradiation with lower breast cancer incidence and mortality (3-5). Numerous preclinical studies have shown that $1,25-(\mathrm{OH})_{2} \mathrm{D}$ inhibits cell proliferation, induces differentiation and apoptosis, and has antiangiogenesis effects in normal and malignant breast cells (6-9). Several epidemiologic studies evaluating the association between vitamin $\mathrm{D}$ and breast cancer risk have yielded inconsistent results (10). Some of these studies assessed the effects of dietary and supplemental intake of parent vitamin D. However, endogenous production through sunlight exposure is the major source of vitamin $\mathrm{D}$ in the body. Measurement of the circulating concentration of 25-OHD provides an integrated measure of vitamin D from all sources-diet, supplements, and sunlight exposure - and is considered the best indicator of vitamin D body stores $(11,12)$.

The Long Island Breast Cancer Study Project was undertaken specifically to investigate environmental factors associated with breast cancer risk (13). We used samples and data previously collected in the Long Island Breast Cancer Study Project to examine the hypothesis that higher plasma 25-OHD levels are associated with decreased breast cancer risk. 


\section{Materials and Methods}

\section{Study population}

Subjects of the Long Island Breast Cancer Study Project are from a population-based casecontrol study conducted on Long Island, New York (13). Breast cancer cases were composed of women over age $20 \mathrm{y}$ who were residents of Nassau and Suffolk counties, spoke English, and were newly diagnosed with in situ or invasive breast cancer between August 1, 1996 and July 31, 1997. For full details of case ascertainment, see the description of the parent study (13). Population-based controls were identified by random digit dialing for those under age $65 \mathrm{y}$, and rosters from the Health Care Financing Administration (now called the Center for Medicare and Medicaid Services) for those age $65 \mathrm{y}$ or older. Controls were frequency matched to the expected age distribution of case women by 5-y age groups. In-person interviews were completed for $82.1 \%$ of eligible cases $(n=1,508)$ and $62.8 \%$ of eligible controls $(n=1,556)$. Of those who completed an interview, $73.1 \%$ of cases and $73.3 \%$ of controls donated a blood sample. Of those who donated a blood sample, we were unable to perform plasma 25-OHD measurements in $6.9 \%$ of cases and $5.8 \%$ of controls, mainly due to insufficient sample to complete the assay. Thus, our final sample size was 1,026 cases and 1,075 controls.

\section{Measurement of plasma 25-OHD}

Plasma samples were stored in aliquots at $-80^{\circ} \mathrm{C}$ until measurement. For quantification of 25-OHD in plasma, we used the Diasorin RIA method. This assay measures two distinct forms of 25-OHD: cutaneously derived vitamin $\mathrm{D}_{3}$ (cholecalciferol) and vitamin $\mathrm{D}_{2}$ (ergocalciferol) derived from supplements or fortified foods (14). Samples were analyzed between September 2007 and December 2007 using a total of eight lots of the assay. Interassay accuracy and precision for quality controls were $+4 \%$ and $15 \%$ at $17 \mathrm{ng} / \mathrm{mL}$, respectively. At $48 \mathrm{ng} / \mathrm{mL}$, interassay accuracy and precision were $+7 \%$ and $18 \%$, and at 57 $\mathrm{ng} / \mathrm{mL}$, these were $+15 \%$ and $15 \%$, respectively. Cases and controls were assayed in each batch and laboratory personnel were blinded to case-control status.

\section{Data collection}

Exposure information comes from two sources-the parent study questionnaire, which was administered by trained interviewers in the subject's home, and laboratory analyses using blood samples to measure plasma 25-OHD concentration (13). As part of the structured questionnaire,${ }^{10}$ respondents were asked about their medical history, reproductive history, family history of cancer, body size changes, dietary factors, recreational physical activities, cigarette smoking and alcohol consumption, occupational and residential history, and demographic characteristics (13).

\section{Statistical methods}

We assessed the association of plasma 25-OHD and breast cancer risk by means of logistic regression with adjustment for potential confounders. First, a test for global significance was conducted using the Wald $\chi^{2}$ test. Odds ratios (OR) and 95\% confidence intervals (95\% CI) were calculated using plasma 25-OHD concentration both as a continuous variable (in $5 \mathrm{ng}$ / $\mathrm{mL}$ increments) and categorical variable divided into four categories $(<20,20-29,30-39$, and $\geq 40 \mathrm{ng} / \mathrm{mL}$ ). Vitamin D deficiency has been variably defined in the literature, but 25 OHD levels above 20 to $32 \mathrm{ng} / \mathrm{mL}(50-80 \mathrm{nmol} / \mathrm{L})$ are considered optimal for bone health $(15,16)$. In our analysis, we defined vitamin D deficiency as plasma $25-\mathrm{OHD}$ of $<20 \mathrm{ng} / \mathrm{mL}$. For simplicity and more model flexibility, we categorized by groupings of $10 \mathrm{ng} / \mathrm{mL}$. This categorization also closely corresponds to the classification into quartiles according to the distribution in the controls. 
All models were adjusted for age at reference as a continuous variable, defined as age at diagnosis for cases and age at identification for controls. We examined potential confounding by the following covariates as continuous variables [age at menarche, age at first pregnancy, parity, body mass index (BMI)] or categorical variables [race (White/nonWhite), first-degree family history of breast cancer, history of benign breast disease, menopausal status, ever use of hormone replacement therapy, physical activity (average number of hours of recreational activity per week by quartile), and season of blood collection (January-March, April-June, July-September, October-December)]. Tests for linear trend were done using each category as an ordinal variable.

Effect modification by menopausal status was examined by including multiplicative interaction terms in the logistic regression model (17). Menopausal status was based on selfreported information collected during the baseline interview, including date of last menstrual period and prior hysterectomy or bilateral oophorectomy. Postmenopausal status was defined as last menstrual period at least 6 mo from the reference date or removal of both ovaries. If a subject had a hysterectomy without removal of both ovaries before her last menstrual period, menopausal status was initially classified as unknown and then reclassified based on the subject's age at reference (13). Differences in risk estimates by hormone receptor status were examined using polytomous logistic regression (17). These models categorized the dependent variable into four groups based on ER and progesterone receptor (PR) positivity, negativity, or unknown status: ER+ and/or PR+, ER-/PR-, ER/PR unknown, and controls. We also examined the associations with the cases restricted to women with invasive breast cancer and those who had not yet initiated chemotherapy by the time of the blood collection.

All tests were two sided and considered to be statistically significant if $\mathrm{P}$ value was $<0.05$. All statistical analyses were conducted using the SAS version 9.1 (SAS Institute).

\section{Results}

Baseline characteristics including demographic information and breast cancer risk factor data for the cases and controls are shown in Table 1. The mean age of cases and controls was 58.6 and 56.1 years, respectively. Over $90 \%$ of participants were White and about twothirds were postmenopausal. Of the 1,026 breast cancer cases, $846(82 \%)$ were invasive and $180(18 \%)$ were in situ. The mean plasma 25-OHD concentration was 27.1 and $29.7 \mathrm{ng} / \mathrm{mL}$ in the cases and controls, respectively $(P<0.0001)$.

Vitamin D deficiency, defined as plasma 25-OHD of $<20 \mathrm{ng} / \mathrm{mL}$, was relatively common among the controls (28\%). Table 2 shows the prevalence of vitamin D deficiency among the controls, based on factors known to influence circulating vita-min D levels. Rates of vitamin $\mathrm{D}$ deficiency did not differ substantially by age. Non-Whites had twice the rate of Whites for vitamin D deficiency. Increasing BMI was associated with a higher rate of vitamin D deficiency. There was also significant seasonal variation in the prevalence of vitamin D deficiency, with the highest rate seen during the late winter-early spring months and the lowest rate during the late summer-early fall months.

Plasma 25-OHD concentration was inversely associated with breast cancer risk in a concentration-dependent fashion $\left(P_{\text {trend }}=0.002\right.$; Table 3$)$. Compared with a reference group with vitamin D deficiency, plasma 25-OHD of $\geq 40 \mathrm{ng} / \mathrm{mL}$ was associated with a $44 \%$ reduction in breast cancer risk. We also analyzed plasma $25-\mathrm{OHD}$ as a continuous variable in the multivariate model and found a significant reduction in breast cancer risk per $5 \mathrm{ng} / \mathrm{mL}$ increment in plasma 25-OHD. 
Multivariate-adjusted estimates based on menopausal status are presented in Table 4. We observed a significant inverse association between plasma 25-OHD levels and breast cancer risk among postmenopausal women but not premenopausal women $($ Pinteraction $=0.024)$. For example, among postmenopausal women, plasma $25-\mathrm{OHD}$ of $\geq 40 \mathrm{ng} / \mathrm{mL}$ was associated with a significant $54 \%$ reduction in breast cancer risk (OR, 0.46; 95\% CI, 0.090.83 ) compared with those with vitamin D deficiency. In contrast, the modest $17 \%$ reduction observed among premenopausal women was not statistically significant (OR, 0.83; 95\% CI, $0.36-1.30)$.

The decrease in the risk of breast cancer associated with circulating vitamin D did not vary based on hormone receptor status (Table 5). We observed a significant inverse association between plasma 25-OHD and risk of breast cancer that were ER+ and/or PR+, ER-/PR-, and ER/PR unknown. Compared with women who were vitamin D deficient, plasma 25OHD of $\geq 40 \mathrm{ng} / \mathrm{mL}$ was associated with a significant $45 \%$ reduction in risk of invasive breast cancer (OR, $\left.0.55 ; 95 \% \mathrm{CI}, 0.39-0.77 ; P_{\text {trend }}=0.003\right)$, whereas the corresponding $37 \%$ decrease observed among women with in situ breast cancer was nonsignificant (OR, $0.63 ; 95 \% \mathrm{CI}, 0.35-1.14 ; P_{\text {trend }}=0.087$; data not shown).

The median difference between time of diagnosis and time of blood draw in the cases was 60 days. We evaluated the potential effects of chemotherapy on plasma 25-OHD levels by excluding the 206 (20\%) cases who had received chemotherapy before blood collection from the analysis. Results were similar comparing the highest category (25-OHD, $\geq 40 \mathrm{ng} /$ $\mathrm{mL}$ ) to the lowest category $(25-\mathrm{OHD},<20 \mathrm{ng} / \mathrm{mL}$ ) for all cases $(\mathrm{OR}, 0.56 ; 95 \% \mathrm{CI}, 0.41-$ 0.78 ) and for cases who had not initiated chemotherapy before blood draw (OR, $0.55 ; 95 \%$ CI, 0.39-0.78; $P_{\text {trend }}=0.003$; data not shown).

\section{Discussion}

In this large population-based case-control study, vitamin D status as measured by plasma 25-OHD levels was inversely associated with breast cancer risk in a concentrationdependent fashion. Women with circulating $25-\mathrm{OHD}$ above $40 \mathrm{ng} / \mathrm{mL}$ had approximately a $40 \%$ reduction in breast cancer risk compared with those who were vitamin D deficient. We found that the risk reduction was more pronounced among postmenopausal women but was similar for hormone receptor-positive and hormone receptor-negative tumors. These results add to a growing body of literature supporting a protective effect of vitamin $\mathrm{D}$ on breast cancer risk, particularly among postmenopausal women.

Several epidemiologic studies examining the association between dietary and supplemental intake of vitamin D and breast cancer risk have yielded inconclusive results (10). However, dietary intake of vitamin D is not a complete measure of vitamin D status and is subject to inaccuracies in recall of dietary intake. Circulating 25-OHD correlates with exogenous intake and endogenous production of vitamin $\mathrm{D}$, is the substrate for conversion to 1,25$(\mathrm{OH})_{2} \mathrm{D}$ in target tissues, and may be the limiting factor in $1,25-(\mathrm{OH})_{2} \mathrm{D}$ synthesis, particularly in extrarenal tissues (18).

Several studies have examined the association between endogenous 25-OHD levels and breast cancer risk (Table 6). Of two small hospital-based case-control studies, one found a significant inverse association for 25-OHD and breast cancer risk (19), and the other study found an inverse association for $1,25-(\mathrm{OH})_{2} \mathrm{D}$ but not $25-\mathrm{OHD}(20)$. These studies were limited by small sample sizes and the use of hospital-based controls. Our results are consistent with the recently reported findings from a large population-based case-control study from Germany (21), which showed that postmenopausal women with serum 25-OHD concentrations of $\geq 75 \mathrm{nmol} / \mathrm{L}(\geq 30 \mathrm{ng} / \mathrm{mL}$ ) had about a $70 \%$ reduction in breast cancer risk 
compared with those with $<30 \mathrm{nmol} / \mathrm{L}(<12 \mathrm{ng} / \mathrm{mL})$. Although statistically insignificant, an inverse association between plasma 25-OHD and 1,25-(OH $)_{2} \mathrm{D}$ and breast cancer risk was observed in the case-control study nested in the Nurses' Health Study (22). Another prospective study of postmenopausal women nested within the Prostate, Lung, Colorectal, and Ovarian Cancer Screening Trial did not observe an association between circulating 25OHD or $1,25-(\mathrm{OH})_{2} \mathrm{D}$ and breast cancer risk (23). Variability in study results may be partially explained by differences in the study populations and the assays used for 25-OHD measurement. In addition, vitamin D seems to be more effective in combating cancer near the time of detection $(24,25)$, which may explain why studies based on 25-OHD levels from stored sera several years before cancer diagnosis often do not find an association. All of the published studies on endogenous 25-OHD concentrations in relation to breast cancer risk have used single measurements of 25-OHD and do not take into account changes in vitamin D levels over time.

Plasma 25-OHD is a useful biomarker for measuring an individual's recent exposure to environmental sources of vitamin D but may not correlate with lifetime patterns of sun exposure or dietary intake. However, the half-life of 25-OHD in the circulation is about 2 months and blood levels are fairly consistent over time $(26,27)$. It is unclear whether plasma $25-\mathrm{OHD}$ varies following a cancer diagnosis and during cancer treatments. After a breast cancer diagnosis, dietary and behavioral changes such as decreased dietary intake of vitamin D or sunlight exposure may occur, which may alter plasma 25-OHD levels. Results of a large nested case-control study showed that higher prediagnostic plasma 25-OHD levels were associated with a trend toward decreasing breast cancer risk (22). In addition, three prospective cohort studies on dietary/supplemental intake of vitamin D and breast cancer risk supported an inverse association (28-30), whereas one did not (31). However, no studies to date have offered a comprehensive assessment of all sources of vitamin D in relation to cancer risk at levels of vitamin D exposure that may be needed for breast cancer prevention.

As for the effects of cancer treatments on plasma 25-OHD levels, a notable change in 25OHD concentration after chemotherapy was not observed in two studies $(32,33)$ or in our own study of premenopausal women undergoing adjuvant chemotherapy for early-stage breast cancer (34). When we restricted our analysis to cases who had not received chemotherapy before blood collection, our results did not change.

Calcium may also have anticancer properties. Vitamin D and calcium are metabolically interrelated and highly correlated dietary factors that may influence breast cancer development through a variety of mechanisms $(31,35)$. A population-based case-control study from Germany examined the independent and joint effects of dietary vitamin D and calcium on premenopausal breast cancer risk (36). In this study, breast cancer risk was inversely associated with vitamin D but not calcium intake (36).

Prior studies have suggested that the association between vitamin D and breast cancer risk may be stronger for premenopausal women compared with postmenopausal women. One cohort study found a reduced risk of breast cancer in association with vitamin $\mathrm{D}$ intake among premenopausal women, but no reduction in breast cancer risk in postmenopausal women (28). In the Women's Health Study, higher intake of vitamin D was moderately associated with a lower risk of breast cancer among premenopausal women, but not postmenopausal women (29). Similarly, the Cancer Prevention Study II Nutrition Cohort observed no association of breast cancer with total vitamin $\mathrm{D}$ intake among postmenopausal women (31). However, these studies did not include evaluation of circulating 25-OHD levels. We observed a significant inverse association between plasma 25-OHD levels and breast cancer risk among postmenopausal women but not premenopausal women. Our 
results may be due to the smaller sample size of the premenopausal group. Compared with postmenopausal women with vitamin D deficiency, those with plasma 25-OHD levels of $\geq 40 \mathrm{ng} / \mathrm{mL}$ had about a $50 \%$ reduction in breast cancer risk. Our results are consistent with the findings of Abbas et al. (21), which showed a protective effect of vitamin D for postmenopausal breast cancer.

We found a significant inverse association of vitamin D levels with breast cancer regardless of hormone receptor status. Recent data from the Nurses' Health Study suggested an inverse association for $\mathrm{ER}-/ \mathrm{PR}-$, but not $\mathrm{ER}+$ and/or PR+ tumors (22). The Iowa Women's Health Study also found a stronger protective effect of vitamin D supplement use among women with breast cancers that were negative rather than positive for ER or PR status (30). Our results suggest that vitamin D may have anticancer effects that are independent of the ER pathway, and that targeting the vitamin D pathway may be a useful preventive strategy for ER-negative, as well as ER-positive breast cancers.

Our study has several strengths, including the population-based sampling of controls, a large sample size that allowed us to stratify the data by potential effect modifiers, and the direct assessment of vitamin D status by an assay that measures both dietary sources of vitamin $\mathrm{D}$ (ergocalciferol) and endogenous vitamin D (cholecalciferol) synthesized in the skin. Vitamin $\mathrm{D}$ assays were completed in a short period of time by the same laboratory and were shown to have high precision. Potential sources of bias in our retrospective case-control design include subject selection and measurement error on plasma 25-OHD concentration. In terms of subject selection, response rates were lower among controls compared with cases, especially among women over the age of 75 years (13). Therefore, these results may not be generalizable to older women. In addition, blood donors differed from those who did not donate blood on a number of factors (13). However, all models included the frequency matching factor age at reference, and adjustment for other known breast cancer risk factors did not appreciably change the effect estimates, and were therefore not included in our final models. Unlike questionnaire exposure data, measurement of circulating 25-OHD levels is not subject to recall bias, although laboratory error is possible. However, this measurement error in plasma 25-OHD is unlikely to differ by case-control status given that all laboratory specimens were labeled with a random number (and cannot be linked back to the subject by the laboratory personnel); thus, this potential source of error cannot explain the observed associations between 25-OHD and breast cancer risk.

Clinical trials of vitamin D supplementation suggest a benefit in the prevention setting. In the Women's Health Initiative, over 36,000 postmenopausal women were randomized to $1,000 \mathrm{mg}$ of calcium carbonate and $400 \mathrm{IU}$ of vitamin D3 or matching placebo for 7 years (37). Although breast cancer incidence did not differ between the two groups, personal supplementation with vitamin D (up to 1,000 IU per day) was allowed, which may have dampened the ability to differentiate between the active and control arms. In a subgroup analysis of women who did not report additional personal supplement use $(n=19,115)$, there was a significant decrease in breast cancer incidence with calcium and vitamin $\mathrm{D}$ compared with placebo (hazard ratio, $0.82 ; 95 \% \mathrm{CI}, 0.70-0.97$ ). Another intervention trial of calcium and 1,100 IU of vitamin D3 daily for 4 years in postmenopausal women found a $60 \%$ reduction in overall cancer incidence compared with placebo (24). However, the number of cancer events was small and the follow-up was only 4 years. In addition, neither this trial nor the Women's Health Initiative can distinguish between the effects of calcium and vitamin D.

In the United States, the Dietary Reference Intake of vitamin D is 200, 400, and $600 \mathrm{IU}$ daily for adults ages $<50,50$ to 70 , and $>70$ years, respectively (38). Oral daily intake of $1,000 \mathrm{IU}$ of vitamin D increases circulating 25-OHD levels by about $10 \mathrm{ng} / \mathrm{mL}$ (39). Given 
the high prevalence of vitamin D deficiency in the general population, to raise plasma 25OHD levels above $40 \mathrm{ng} / \mathrm{mL}$, the putative target level for breast cancer risk reduction, women would have to consume about 4,000 IU daily, which exceeds the National Academy of Sciences upper limit of 2,000 IU/day (38). In the time since this upper safety limit was set in 1997, accumulating evidence in trials of healthy adults suggests that doses well above those recommended currently are safe (40). However, controversy in this field remains.

In summary, our study adds to a growing body of evidence that adequate vitamin D stores may prevent the development of breast cancer. The protective effect of vitamin D was stronger among postmenopausal women, but was similar for hormone receptor-positive and hormone receptor-negative tumors. These results represent an important public health finding, as women with low circulating 25-OHD levels may benefit from vitamin D supplementation for breast cancer risk reduction. Whereas circulating 25-OHD levels of $>32$ $\mathrm{ng} / \mathrm{mL}$ are associated with normal mineral metabolism, data from our study and others (41) suggest that the optimal level for breast cancer prevention is $\geq 40 \mathrm{ng} / \mathrm{mL}$. Future studies should include repeated measures of 25-OHD to determine whether changes over time are linked to cancer risk. In addition, well-designed clinical trials are necessary to determine whether vitamin D supplementation is effective for breast cancer chemoprevention.

\section{Acknowledgments}

Grant support: Grants nos. U01 CA/ES66572, P30ES09089, P30ES10126, and K24 AR052665 from the NIH, an award from the Breast Cancer Research Foundation and the Jean Sindab Foundation, and gifts from private citizens. This publication was also made possible by Grant Number UL1 RR024156 from the National Center for Research Resources (NCRR), a component of the NIH, and NIH Roadmap for Medical Research. Its contents are solely the responsibility of the authors and do not necessarily represent the official view of NCRR or NIH. Information on NCRR is available at http://www.ncrr.nih.gov/. Information on Re-engineering the Clinical Research Enterprise can be obtained from http://nihroadmap.nih.gov/clinicalresearch/overview-translational.asp.

\section{References}

1. Zehnder D, Bland R, Williams MC, et al. Extrarenal expression of 25-hydroxyvitamin d(3)-1 $\alpha$ hydroxylase. J Clin Endocrinol Metab. 2001; 86:888-94. [PubMed: 11158062]

2. Colston KW, Hansen CM. Mechanisms implicated in the growth regulatory effects of vitamin D in breast cancer. Endocr Relat Cancer. 2002; 9:45-59. [PubMed: 11914182]

3. Gorham ED, Garland FC, Garland CF. Sunlight and breast cancer incidence in the USSR. Int J Epidemiol. 1990; 19:820-4. [PubMed: 2084008]

4. Garland FC, Garland CF, Gorham ED, Young JF. Geographic variation in breast cancer mortality in the United States: a hypothesis involving exposure to solar radiation. Prev Med. 1990; 19:614-22. [PubMed: 2263572]

5. Grant WB. An ecologic study of dietary and solar ultraviolet-B links to breast carcinoma mortality rates. Cancer. 2002; 94:272-81. [PubMed: 11815987]

6. Welsh J. Vitamin D and breast cancer: insights from animal models. Am J Clin Nutr. 2004; 80:1721-4S.

7. Colston KW, Berger U, Coombes RC. Possible role for vitamin D in controlling breast cancer cell proliferation. Lancet. 1989; 1:188-91. [PubMed: 2563099]

8. Saez S, Falette N, Guillot C, et al. William L. McGuire Memorial Symposium. 1,25(OH)2D3 modulation of mammary tumor cell growth in vitro and in vivo. Breast Cancer Res Treat. 1993; 27:69-81. [PubMed: 8260731]

9. Mantell DJ, Owens PE, Bundred NJ, Mawer EB, Canfield AE. $1 \alpha, 25$-dihydroxyvitamin D(3) inhibits angiogenesis in vitro and in vivo. Circ Res. 2000; 87:214-20. [PubMed: 10926872]

10. Cui Y, Rohan TE. Vitamin D, calcium, and breast cancer risk: a review. Cancer Epidemiol Biomarkers Prev. 2006; 15:1427-37. [PubMed: 16896028]

11. Iqbal SJ. Vitamin D metabolism and the clinical aspects of measuring metabolites. Ann Clin Biochem. 1994; 31:109-24. [PubMed: 8060088] 
12. Hollis BW. Assessment of vitamin D nutritional and hormonal status: what to measure and how to do it. Calcif Tissue Int. 1996; 58:4-5. [PubMed: 8825231]

13. Gammon MD, Neugut AI, Santella RM, et al. The Long Island Breast Cancer Study Project: description of a multi-institutional collaboration to identify environmental risk factors for breast cancer. Breast Cancer Res Treat. 2002; 74:235-54. [PubMed: 12206514]

14. Roth HJ, Schmidt-Gayk H, Weber H, Niederau C. Accuracy and clinical implications of seven 25hydroxyvitamin D methods compared with liquid chromatography-tandem mass spectrometry as a reference. Ann Clin Biochem. 2008; 45:153-9. [PubMed: 18325178]

15. Dawson-Hughes B, Heaney RP, Holick MF, et al. Estimates of optimal vitamin D status. Osteoporos Int. 2005; 16:713-6. [PubMed: 15776217]

16. Yetley EA. Assessing the vitamin D status of the US population. Am J Clin Nutr. 2008; 88:558$64 \mathrm{~S}$.

17. Hosmer, DW.; Lemeshow, S. Applied Logistic Regressioned. John Wiley \& Sons; New York (NY): 1989.

18. Newmark HL, Heaney RP, Lachance PA. Should calcium and vitamin D be added to the current enrichment program for cereal-grain products? Am J Clin Nutr. 2004; 80:264-70. [PubMed: 15277144]

19. Lowe LC, Guy M, Mansi JL, et al. Plasma 25-hydroxy vitamin D concentrations, vitamin D receptor genotype and breast cancer risk in a UK Caucasian population. Eur J Cancer. 2005; 41:1164-9. [PubMed: 15911240]

20. Janowsky EC, Lester GE, Weinberg CR, et al. Association between low levels of 1,25dihydroxyvitamin D and breast cancer risk. Public Health Nutr. 1999; 2:283-91. [PubMed: 10512563]

21. Abbas S, Linseisen J, Slanger T, et al. Serum 25-hydroxyvitamin D and risk of post-menopausal breast cancer-results of a large case-control study. Carcinogenesis. 2008; 29:93-9. [PubMed: 17974532]

22. Bertone-Johnson ER, Chen WY, Holick MF, et al. Plasma 25-hydroxyvitamin D and 1,25dihydroxyvitamin D and risk of breast cancer. Cancer Epidemiol Biomarkers Prev. 2005; 14:1991-7. [PubMed: 16103450]

23. Freedman DM, Chang SC, Falk RT, et al. Serum levels of vitamin d metabolites and breast cancer risk in the prostate, lung, colorectal, and ovarian cancer screening trial. Cancer Epidemiol Biomarkers Prev. 2008; 17:889-94. [PubMed: 18381472]

24. Lappe JM, Travers-Gustafson D, Davies KM, Recker RR, Heaney RP. Vitamin D and calcium supplementation reduces cancer risk: results of a randomized trial. Am J Clin Nutr. 2007; 85:1586-91. [PubMed: 17556697]

25. Zhou W, Heist RS, Liu G, et al. Circulating 25-hydroxyvitamin D levels predict survival in earlystage non-small-cell lung cancer patients. J Clin Oncol. 2007; 25:479-85. [PubMed: 17290055]

26. Feskanich D, Ma J, Fuchs CS, et al. Plasma vitamin D metabolites and risk of colorectal cancer in women. Cancer Epidemiol Biomarkers Prev. 2004; 13:1502-8. [PubMed: 15342452]

27. Vieth R, Cole DE, Hawker GA, Trang HM, Rubin LA. Wintertime vitamin D insufficiency is common in young Canadian women, and their vitamin D intake does not prevent it. Eur J Clin Nutr. 2001; 55:1091-7. [PubMed: 11781676]

28. Shin MH, Holmes MD, Hankinson SE, et al. Intake of dairy products, calcium, and vitamin d and risk of breast cancer. J Natl Cancer Inst. 2002; 94:1301-11. [PubMed: 12208895]

29. Lin J, Manson JE, Lee IM, et al. Intakes of calcium and vitamin D and breast cancer risk in women. Arch Intern Med. 2007; 167:1050-9. [PubMed: 17533208]

30. Robien K, Cutler GJ, Lazovich D. Vitamin D intake and breast cancer risk in postmenopausal women: the Iowa Women's Health Study. Cancer Causes Control. 2007; 18:775-82. [PubMed: 17549593]

31. McCullough ML, Rodriguez C, Diver WR, et al. Dairy, calcium, and vitamin D intake and postmenopausal breast cancer risk in the Cancer Prevention Study II Nutrition Cohort. Cancer Epidemiol Biomarkers Prev. 2005; 14:2898-904. [PubMed: 16365007] 
32. Kailajarvi ME, Salminen EK, Paija OM, et al. Serum bone markers in breast cancer patients during 5-fluorouracil, epirubicin and cyclophosphamide (FEC) therapy. Anticancer Res. 2004; 24:12714. [PubMed: 15154659]

33. Gao Y, Shimizu M, Yamada S, Ozaki Y, Aso T. The effects of chemotherapy including cisplatin on vitamin D metabolism. Endocr J. 1993; 40:737-42. [PubMed: 7951544]

34. Crew KD, Shane E, Cremers S, et al. High prevalence of vitamin D deficiency in a multi-ethnic cohort of premenopausal breast cancer patients. Proceedings of the American Society of Clinical Oncology. 2008

35. Jacobson EA, James KA, Newmark HL, Carroll KK. Effects of dietary fat, calcium, and vitamin D on growth and mammary tumorigenesis induced by 7,12-dimethylbenz(a)anthracene in female Sprague-Dawley rats. Cancer Res. 1989; 49:6300-3. [PubMed: 2509066]

36. Abbas S, Linseisen J, Chang-Claude J. Dietary vitamin D and calcium intake and premenopausal breast cancer risk in a German case-control study. Nutr Cancer. 2007; 59:54-61. [PubMed: 17927502]

37. Chlebowski RT, Johnson KC, Kooperberg C, et al. The Women's Health Initiative randomized trial of calcium plus vitamin D: effects on breast cancer and arthralgias. Proceedings of the American Society of Clinical Oncology. 2006

38. National Academy of Sciences. Institute of Medicine. Food and Nutrition Board. Dietary Reference Intakes for Calcium, Phosphorus, Magnesium, Vitamin D, and Fluorideed. National Academy Press; Washington (DC): 1997. p. 7-30.

39. Heaney RP, Davies KM, Chen TC, Holick MF, Barger-Lux MJ. Human serum 25hydroxycholecalciferol response to extended oral dosing with cholecalciferol. Am J Clin Nutr. 2003; 77:204-10. [PubMed: 12499343]

40. Hathcock JN, Shao A, Vieth R, Heaney R. Risk assessment for vitamin D. Am J Clin Nutr. 2007; 85:6-18. [PubMed: 17209171]

41. Garland CF, Gorham ED, Mohr SB, et al. Vitamin D and prevention of breast cancer: pooled analysis. J Steroid Biochem Mol Biol. 2007; 103:708-11. [PubMed: 17368188] 
Table 1

Baseline characteristics of the subset of breast cancer cases and controls with plasma 25-OHD levels, Long Island Breast Cancer Study Project (1996-1997)

\begin{tabular}{|lcc|}
\hline Baseline Characteristics & Cases $(\boldsymbol{n}=\mathbf{1 , 0 2 6})$ & Controls $(\boldsymbol{n}=\mathbf{1 , 0 7 5})$ \\
\hline Age (y) & \multicolumn{2}{c|}{ Mean (SD) } \\
Age at menarche (y) & $58.6(12.5)$ & $56.1(12.5)$ \\
Parity ${ }^{*}$ & $12.6(1.5)$ & $12.5(1.6)$ \\
Age at first birth $(\mathrm{y})^{*}$ & $2.4(1.6)$ & $2.5(1.6)$ \\
BMI $\left(\mathrm{kg} / \mathrm{m}^{2}\right)$ & $25.4(4.6)$ & $25.1(4.5)$ \\
Plasma 25-OHD (ng/mL) & $26.6(5.6)$ & $26.3(5.8)$ \\
& $27.1(13.0)$ & $29.7(15.1)$ \\
White & \multicolumn{2}{c}{ Percentage $(\%)$} \\
Postmenopausal & 94.4 & 92.4 \\
First-degree family history of breast cancer & 67.5 & 64.6 \\
History of benign breast disease & 18.5 & 13.8 \\
Ever breastfeeding & 19.3 & 13.7 \\
Ever hormone replacement therapy & 34.2 & 36.2 \\
\hline
\end{tabular}

*Among parous women $(n=890$ cases and 955 controls $)$. 
Table 2

Prevalence of vitamin D deficiency (plasma 25-OHD, <20 ng/mL) by age, race, BMI, and season of blood draw among controls

\begin{tabular}{|lrr|}
\hline Characteristics among controls & Vitamin D deficiency $\boldsymbol{n}(\%)$ & $\mathbf{P}^{*}$ \\
\hline Age, y & $29(29)$ & 0.480 \\
$<40$ & $92(32)$ & \\
$40-50$ & $79(27)$ & \\
$51-60$ & $58(25)$ & \\
$61-70$ & $44(29)$ & \\
$>70$ & & \\
Race & $262(26)$ & $<0.001$ \\
White & $40(49)$ & \\
Non- White & & \\
BMI, kg/m ${ }^{2}$ & $121(22)$ & $<0.001$ \\
$<25$ & $101(32)$ & \\
$25-30$ & $80(37)$ & \\
$>30$ & & \\
Season of blood draw & $99(38)$ & $<0.001$ \\
Jan-Mar & $99(34)$ & \\
Apr-Jun & $26(12)$ & \\
July-Sept & $78(26)$ & \\
Oct-Dec & & \\
\hline
\end{tabular}

Based on $\mathrm{X}^{2}$ test. 


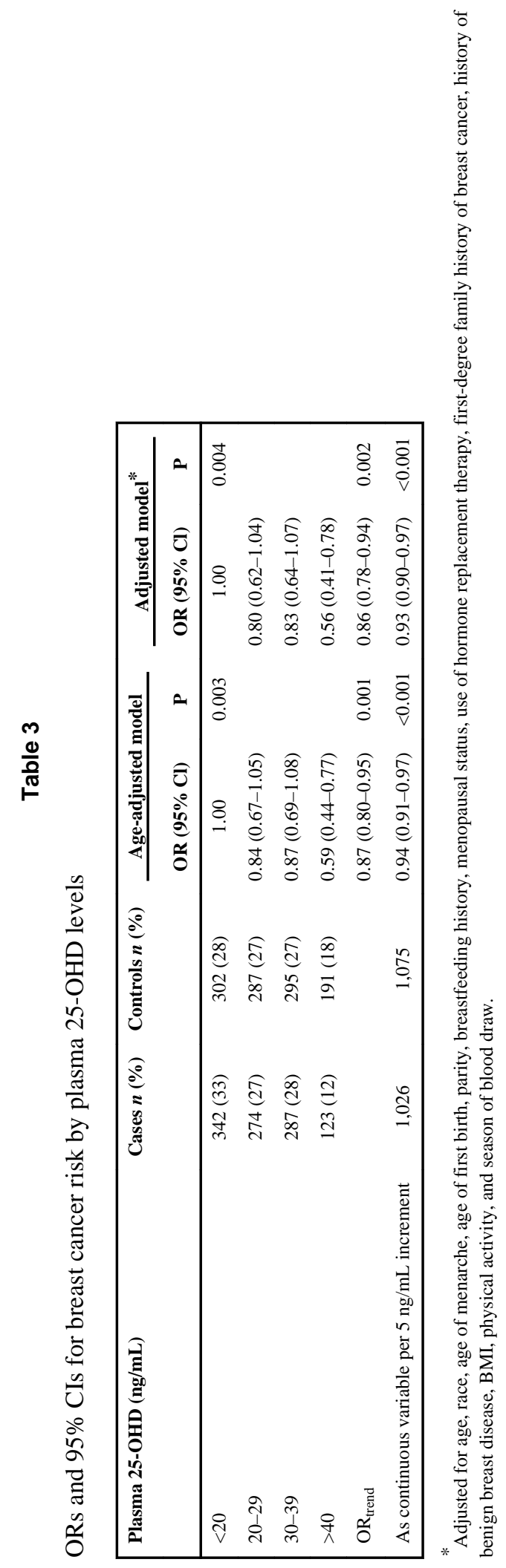

Cancer Prev Res (Phila). Author manuscript; available in PMC 2011 April 15. 
Table 4

Multivariate-adjusted ORs and 95\% CIs for breast cancer risk by plasma 25-OHD levels (ng/mL) stratified by menopausal status

\begin{tabular}{|lcrc|}
\hline Menopausal Status & Cases & Controls & OR (95\% CI) \\
\hline Premenopausal & & & \\
$\quad<20$ & 98 & 117 & 1.00 \\
$20-29$ & 79 & 82 & $1.07(0.65-1.49)$ \\
$30-39$ & 101 & 98 & $1.20(0.81-1.59)$ \\
$\geq 40$ & 48 & 67 & $0.83(0.36-1.30)$ \\
$P_{\text {trend }}$ & & & 0.821 \\
As continuous variable per 5 ng/mL increment & 326 & 364 & $0.97(0.92-1.02)$ \\
Postmenopausal & & & \\
$<20$ & 232 & 173 & 1.00 \\
$20-29$ & 190 & 196 & $0.70(0.41-0.99)$ \\
$30-39$ & 180 & 183 & $0.70(0.40-1.00)$ \\
$\quad 40$ & 74 & 113 & $0.46(0.09-0.83)$ \\
$P_{\text {trend }}$ & & & $<0.001$ \\
As continuous variable per $5 \mathrm{ng} / \mathrm{mL}$ increment & 676 & 665 & $0.92(0.89-0.96)$ \\
\hline
\end{tabular}

* Adjusted for age, race, BMI, and season of blood draw. 
Table 6

Endogenous 25-OHD levels and breast cancer risk

\begin{tabular}{|c|c|c|c|c|}
\hline Study & Study Design & No. cases/controls & Comparison $*$ & OR $(95 \% \mathrm{CI})$ \\
\hline Lowe et al., 2005 (19) & Hospital-based case-control & $179 / 179$ & $25-\mathrm{OHD}(\mathrm{ng} / \mathrm{mL})<20 \mathrm{vs}>60$ & $5.83(2.31-14.7)$ \\
\hline Abbas et al., 2008 (21) & Population-based case-control & $1,394 / 1,365$ & $25-\mathrm{OHD}(\mathrm{ng} / \mathrm{mL}) \geq 30$ vs $<12$ & $0.31(0.24-0.42)$ \\
\hline Crew et al. & Population-based case-control & $1,026 / 1,075$ & $25-\mathrm{OHD}(\mathrm{ng} / \mathrm{mL}) \geq 40$ vs $<20$ & $0.56(0.41-0.78)$ \\
\hline $\begin{array}{l}\text { Bertone-Johnson et al., } 2005 \\
\text { (22) }\end{array}$ & Nested case-control & $701 / 724$ & $25-\mathrm{OHD}(\mathrm{ng} / \mathrm{mL}) \geq 40 \mathrm{vs} \leq 20^{\dagger}$ & $0.73(0.49-1.07)$ \\
\hline Freedman et al., 2008 (23) & Nested case-control & $1,005 / 1,005$ & $25-\mathrm{OHD}(\mathrm{ng} / \mathrm{mL}) \geq 33.7$ vs $<18.3$ & $1.04(0.75-1.45)$ \\
\hline
\end{tabular}

For circulating concentration of $25-\mathrm{OHD}, 1 \mathrm{ng} / \mathrm{mL}=2.5 \mathrm{nmol} / \mathrm{L}$.

${ }^{\dagger}$ For this study, breast cancer risk was analyzed by quintiles of plasma 25-OHD. Quintile cut points differed in the three batches of plasma 25OHD measurements. 